\title{
Determination of Anserine, Carnosine, and Other Histidine Compounds in Muscle Extractives ${ }^{1}$
}

\author{
ADAM A. CHRISTMAN \\ Department of Biological Chemistry, The University of Michigan, \\ Ann Arbor, Michigan 48104
}

Re-submitted August 18, 1970

A recent renewal of interest in the muscle extractives carnosine ( $\beta$-alanylhistidine) and anserine ${ }^{2}$ ( $\beta$-alanyl-1-methylhistidine), their component imidazoyl amino acids, as well as 3 -methylhistidine and the dipeptide homocarnosine ( $\gamma$-aminobutyrylhistidine), may be noted (14). The present paper deals with the determination of these dipeptides and the free imidazoyl amino acids in muscle. The muscle is finely minced with scissors and transferred to a microhomogenizer for more complete disintegration. The colloidal mixture is extracted three times with small portions of boiling water and the extracts passed through a glass wool filter. Removal of the proteins by trichloroacetic acid or sulfosalicyclic acid at a final concentration of $3 \%$ yields clear filtrates which can be applied directly to the resin columns of the amino acid analyzer for separation and quantitation. Filtrates obtained by both methods of deproteinization yield nearly identical values for the peptides and amino acids under consideration. If the analysis is not to be done promptly after deproteinization the filtrates should be kept in a frozen state.

Breast muscle of pigeons, various muscles of rats and man, and leg muscles of monkeys have been analyzed. The muscle samples from monkeys were obtained by biopsy, the human samples from autopsy material and from various muscles made available during surgical procedures. Amounts from 22 to $200 \mathrm{mg}$ of muscle have been used but whenever possible the filtrate put on the resin column should contain the equivalent of 40 to $70 \mathrm{mg}$ of muscle in 1,2 , or $3 \mathrm{ml}$. Since the

${ }^{1}$ This work was supported in part by Rackham Project 313 and by the grant (HD-01233) made to Halvor N. Christensen by the Institute for Child Health and Human Developmenl, Nalional Institutes of Health, USPHS.

${ }^{2}$ The anserine, carnosine, and imidazoyl amino acids were obtained from Calbiochem. Los Angeles, California. The homocarnosine was a product of Sigma Chomical Company, St. Louis, Missouri. 
results are conventionally calculated as $\mu$ moles/gm wet muscle, the freshly obtained muscle is dropped in dry ice and weighed immediately. In some experiments the amount of muscle available was sufficient to pcrmit a sample to be used for the water content, which in most cases was between 74 and $77 \%$.

There appears to be no problem of a rapid loss of anserine and carnosine from rat muscle by hydrolysis or deamination. The content of these compounds in a leg muscle removed and deproteinized immediately after the death of the rat is essentially the same as that from the corresponding muscle of the other leg, which had remained in situ for 20 to $30 \mathrm{~min}$ before removal and deproteinization.

If only the anserine, carnosine, and histidine content of the muscle is desired, these components can be quickly and accurately determined on the $20 \times 0.9 \mathrm{~cm}$ column of the Phoenix amino acid analyzer (model $\mathrm{K}, 8200 \mathrm{~B}$ ) containing the resin type $\mathrm{xx} 8-20$-I. A $0.35 M$ sodium citrate buffer ( $\mathrm{pH}$ 5.28) (5) is pumped through the column $(17 \mathrm{~cm}$ resin depth) at the rate of $40 \mathrm{ml} / \mathrm{hr}$ for the first hour and at $30 \mathrm{ml} / \mathrm{hr}$ for the remaining time. The temperature is held at $30^{\circ} \mathrm{C}$ for first the half hour and then automatically adjusted to $50^{\circ}$ for the remainder of the determination. The ratio of buffer to ninhydrin (6) in all of these experiments was $2: 1$. Ornithine, lysine, anserine, carnosine, and histidine contained in a $0.2 M$ citrate buffer ( $\mathrm{pH} 2.2$ ) (5) are well separated by this procedure. In a typical experiment, elution peaks of the compounds in the order listed above occurred at 90, 98, 112, 126, and $134 \mathrm{~min}$, corresponding to the passage of $55,59,66,73$, and $77 \mathrm{ml}$ of the eluate through the resin. The $\mathrm{NH}_{4}^{+}$present in small amounts in the buffer and in larger amounts in the acid deproteinizing reagents reach its peak at $146 \mathrm{~min}$, corresponding to the passage of $83 \mathrm{ml}$ of buffer. If 1-methylhistidine and 3-methylhistidine were present in the standard mixture, the 1-methylhistidine was eluted from the $20 \mathrm{~cm}$ column shortly after the histidine so that the peaks tended to fuse. The 3-methylhistidine elution followed that of the 1-methylhistidine but was so similar to that of the $\mathrm{NH}_{4}{ }^{+}$that the peaks tended to overlap.

The elution volume of tryptophan from the $20 \mathrm{~cm}$ column by this procedure was almost identical with that of lysine. Apparently this behavior was related to the $30 \mathrm{~min}$ elution at $30^{\circ}$, since in the method to be discussed below using the $60 \mathrm{~cm}$ column a similar overlapping of tryptophan and lysine occurred if part of the elution was made at $30^{\circ}$. On the $20 \mathrm{~cm}$ column, the preliminary elution at $30^{\circ}$ is necessary to obtain an adequate separation of lysine and anserine. For the present study the analytical values for ornithine, lysine, and tryptophan in muscle were of no interest but since they are present in small amounts 
in muscle they were included in the standards as markers to establish the time at which the baseline must be adjusted.

If the imidazoyl amino acids and homocarnosine as well as anserine and carnosine are to be determined, the $60 \mathrm{~cm}$ column of the Phoenix amino acid analyzer (spherical resin type $\mathrm{xx}-8-60-\mathrm{I}$ ) is used. The buffer ( $\mathrm{pH} 5.28,0.35 \mathrm{M}$ soduim citrate) is pumped through the column at $50^{\circ}$ at the rate of $80 \mathrm{ml} / \mathrm{hr}$ for $2 \mathrm{hr}$ and then at the rate of $30 \mathrm{ml} / \mathrm{hr}$ for the remaining time. The ninhydrin reagent at the rate of $15 \mathrm{ml} / \mathrm{hr}$ is introduced only when the flow rate of the buffer has been adjusted to $30 \mathrm{ml} / \mathrm{hr}$. By this time the neutral amino acids have passed through the reaction bath.

Figure 1 illustrates the separation of the components of a standard solution containing ornithine, lysine, anserine, homocarnosine, carnosine, histidine, 1-methylhistidine, 3-methylhistidine, and $\mathrm{NH}_{4}{ }^{+}$in $0.2 M$ citrate buffer ( $\mathrm{pH}$ 2.2). The elution peaks of these compounds in the order given above occurred after the passage of $177,186,199,213,226,243$, 253,264 , and $279 \mathrm{ml}$ of the buffer. Approximately $335 \mathrm{~min}$ are required for the elution of all the histidine compounds and an additional $50 \mathrm{~min}$ for the removal of the ammonium ion.

$\Lambda$ s indicated previously, tryptophan under certain conditions may be eluted with lysine. Creatine present in some muscles to the extent of $4 \mu$ moles $/ 100 \mathrm{mg}$ and its acid hydrolysis product creatinine are compounds in addition to tryptophan that might be eluted from the column at a rate that would interfere with the determination of the histidine derivatives. A standard containing $1.0 \mu$ mole tryptophan, $2.0 \mu$ moles creatine, and $1.8 \mu$ moles creatinine was carried through the elution procedure

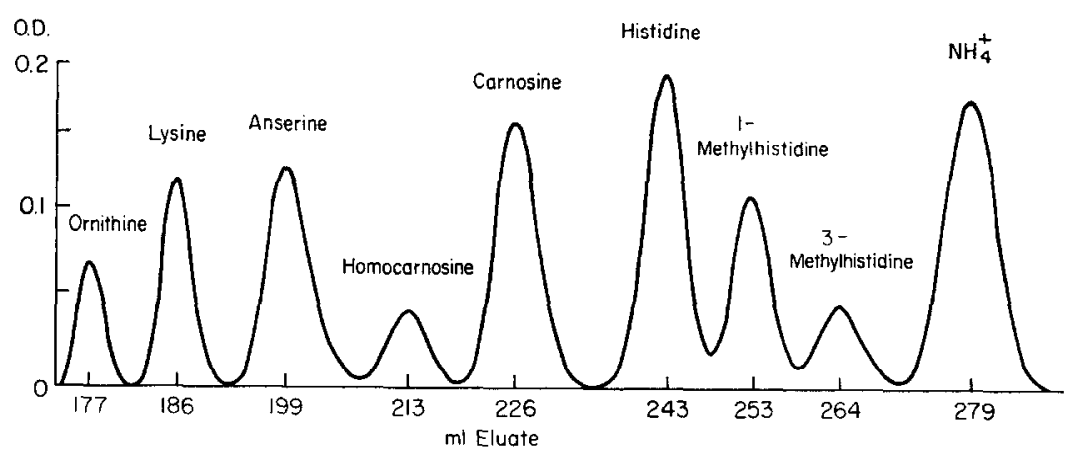

FIg. 1. Resolution on $56 \mathrm{~cm}$ column of resin xx8-60-I at $50^{\circ} \mathrm{C}$. Sodium eitrate buffer $(0.35 M, \mathrm{pH} 5.28)$. Rate $80 \mathrm{ml} / \mathrm{hr}$ for $2 \mathrm{hr}, 30 \mathrm{ml} / \mathrm{hr}$ for remaining period. umoles: ornithine 0.1 , lysine 0.2 , anserine 0.4 , homocarnosine 0.1 , carnosine 0.4 , histidine $0.4,1$-methylhistidine $0.2,3$-methylhistidine $0.1, \mathrm{NH}_{4}^{+} 0.2$ plus buffer impurity of approximately $0.01 \mu$ moles. 
for $340 \mathrm{~min}$. No absorption peaks were observed in the area corresponding to the passage of 180 to $264 \mathrm{ml}$ of buffer, thus eliminating the possibility of these compounds interfering with the analyses of the histidine derivatives of muscle cxtracts. During the course of analyses of various muscle samples from animals of different species, no evidence has been obtained of compounds other than those contained in the standard solutions.

Although the procedure outlined above for the separation of nine basic compounds was designed for the Phoenix amino acid analyzer, preliminary studies have shown that similar separations may be obtained with the Beckman amino acid analyzer. Since the Beckman instrument has a more sensitive optical system than the Phoenix used in these studies, the former should prove useful for analyses when only small samples can be obtained.

Figure 2 shows that most of the compounds resolved on the $60 \mathrm{~cm}$ column of the Phoenix amino acid analyzer using the spherical resin (type $x \times 8-60-1$ ) can also be scparated on the $60 \mathrm{~cm}$ column of the Beckman analyzer (model 120C) with spherical resin UR30. The buffer $(0.35 M, \mathrm{pH} 5.28$, sodium citrate) was pumped through the column at $68 \mathrm{ml} / \mathrm{hr}$. The temperature was held at $40^{\circ} \mathrm{C}$ for $1.5 \mathrm{hr}$ and then adjusted to $56^{\circ}$ for the remainder of the determination. The standard solution placed on the column contained ornithine, lysine, anserine, carnosine, histidine, and 1-methylhistidine. The small amount of $\mathrm{NH}_{4}{ }^{+}$ was introduced as an impurity in the buffer. Figure 2 shows that the elution peaks of these compounds in the order given above occur at 199 , $207,223,245,256,279$, and $306 \mathrm{ml}$. If both 1-methylhistidine and 3 methylhistidine were included in the standard, a single elution peak

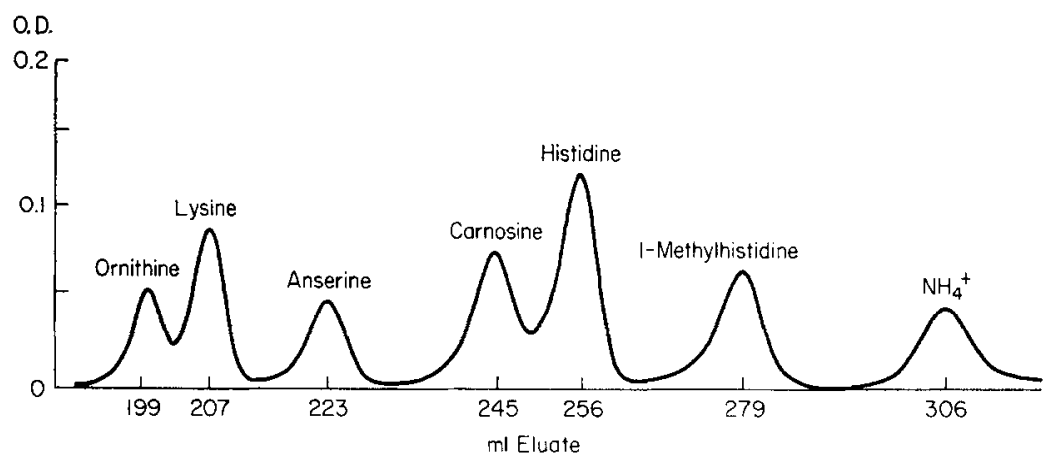

FIg. 2. Resolution on $56 \mathrm{~cm}$ column of spherical resin UR30 at $40^{\circ} \mathrm{C}$ for $1.5 \mathrm{hr}$ and $56^{\circ}$ for remaining period. Sodium eitrate buffer $(0.35 M, p M$ 5.28). Rate 68 $\mathrm{ml} / \mathrm{hr}$. $\mu$ moles: ornithine 0.025 lysine 0.05 , anserine 0.1 , carnosine 0.1 , histidine 0.1 , 1-methylhistidine $0.05, \mathrm{NH}_{4}{ }^{+}$buffer impurity of approximately $0.01 \mu$ mole. 
at $279 \mathrm{ml}$ was obtained. It should be noted that the order of elution of these basic compounds is essentially the same on the UR30 resin as on the xx8-60-I resin if the single buffer ( $\mathrm{pH} 5.28,0.35 M$ citrate) is used.

If homocarnosine is contained in the standard solution its elution peak $(228 \mathrm{ml})$ is so close to that of anserine $(223 \mathrm{ml})$, that a twin peak is formed which would permit identification but make quantitative determination impossible. With a flow rate of $80 \mathrm{ml} / \mathrm{hr}$ for $1.5 \mathrm{hr}$, followed by a flow rate of $40 \mathrm{ml} / \mathrm{hr}$ for the remaining time (temperature at $50^{\circ} \mathrm{C}$ ), the elution of homocarnosine comes midway between anserine and carnosine. All of the other constituents of the standard solution except the 1 - and 3-methylhistidine are well separated. The time required is approximately $1 \mathrm{hr}$ more than for the method used in the experiment shown in Fig. 2.

By the method shown in Fig. 1, no 3-methylhistidine and only traces of 1-methylhistidine have been found in the hot water extracts of different muscles of four mammalian species. For this reason no further effort was made to modify the procedure using the UR30 resin to effect the separation of the two methylhistidines. Juehl and Adelstein (7) have described two systems using a $55 \mathrm{~cm}$ column of UR30 by which 3-methylhistidine can be separated from other hydrolytic products of a protein.

The major part of the standardization work on the Phoenix amino acid analyzer had been completed before the publication of the article by Long and Geiger (8). A $33 \mathrm{~cm}$ column which was not available on our instrument was used in their experiments (Phoenix model K-8000 $\mathrm{B})$. The separations of the basic amino acids and peptides on a $7 \%$ cross-linked and on a $8 \%$ cross-linked resin (height $27 \mathrm{~cm}$ ) were compared. A mixture of the two resins containing $25 \%$ of the $7 \%$ crosslinked resin was shown to be more effective than either of the single types. In addition to the use of a shorter column $(33 \mathrm{vs} .60 \mathrm{~cm})$ of a mixture of resins, their procedure differs from that of the present report (Fig. 1) in two respects: (1) a change from a pH of 4.23 to 5.28 at $240 \mathrm{~min}$; (2) a temperature adjustment of $41^{\circ} \mathrm{C}$ to $55^{\circ}$ after $240 \mathrm{~min}$. The differences in the elution pattern of the histidine, the methyl-substituted histidines, and the dipeptides anserine and carnosine by the two procedures are quite different. Figures 4,5 , and 6 of the paper of Long and Geiger (8) show that the elution of $\mathrm{NH}_{4}^{+}$, 1-methylhistidine, histidine, and 3-methylhistidine precedes that of the anserine and carnosine. Figure 1 in the present paper indicates that the order of elution is anserine, carnosine, histidine, 1-methylhistidine, 3-methylhistidine, and $\mathrm{NH}_{4}{ }^{+}$. The time interval of $40 \mathrm{~min}$ between the elution peaks of the 
3-methylhistidine and the $\mathrm{NH}_{4}{ }^{+}$is a fortunate circumstance since the high $\mathrm{NH}_{4}{ }^{+}$in the filtrates of muscle tissue derived from the $\mathrm{NH}_{4}{ }^{+}$of the deproteinizing reagents does not interfere with the determination of the histidine derivatives by our procedure.

The analytical methods described in this paper were designed primarily for the determination of anserine and carnosine of muscle with a secondary interest in the imidazoyl amino acids. If only the content of the dipeptides is wanted, the analysis on the $17 \mathrm{~cm}$ column (resin $\mathrm{xx} 8-201$ ) can be terminated in $85 \mathrm{~min}$ and on the $56 \mathrm{~cm}$ column (resin $\mathrm{xx} 8-60-\mathrm{I})$ in the $270 \mathrm{~min}$. Duplicate analyses of a muscle filtrate on both the short $(20 \mathrm{~cm})$ and the long $(60 \mathrm{~cm})$ column have given values for anserine and carnosine which agree within $5 \%$. The advantage of the longer column is that histidine, 1-methylhistidine, and 3-methylhistidine can be determined even if present at low concentrations. For the complete analysis including the elution of the $\mathrm{NH}_{4}^{+}$, the $56 \mathrm{~cm}$ column of $\mathrm{xx} 8-60$-I resin (Fig. 1) requires $385 \mathrm{~min}$ as compared to 280 min for the $56 \mathrm{~cm}$ column of the UR30 resin (Fig. 2).

Davies and Scriver (4) have stated that anserine is absent from human muscle but give no reference to support their statement. Perry et al. (3) report the analysis of one sample of human muscle obtained at autopsy that contained carnosine but not a trace of anserine. The extensive review of du Vigneaud and Behrens (9) provides no information on this point. During the three years of the present study many samples of human muscles have been analyzed for anserine and carnosine. The first 17 samples of muscle were obtained on autopsy from hospital patients who had died from a variety of causes. The interval between death and autopsy varied from 2 to $24 \mathrm{hr}$. Although carnosine was always present, in no case was there a trace anserine. It seemed likely that the anserine might have disappeared from the muscle between the time of death and the procurement of the sample. Small samples of human muscle obtained during surgery were dropped in dry ice and taken to the laboratory for immediate analysis. Samples of striated muscle obtained from 25 individuals ranging in age from 1.5 to 80 years showed a small trace or no anserine but carnosine levels which ranged from 1 to $8 \mu \mathrm{moles} / \mathrm{gm}$ muscle (wet weight).

It has been proposed that anserine and carnosine may be present in muscles as phosphate derivates. The failure to find anserine in human muscles suggested that a more acidic derivative might have been eluted from the resin column before the ninhydrin reagent was mixed with the eluate. To check this possibility hydrochloric acid was added to an aliquot of a trichloroacetic acid filtrate of human muscle to bring the final concentration to 1.0 normal. The resulting solution was heated 
in a boiling water bath for $30 \mathrm{~min}$ and cooled and the $\mathrm{pH}$ adjusted to that of the original filtrate. The analysis of this hydrolyzed sample was compared with that of the original filtrate. The increase in free histidine was equivalent to the loss of carnosine but there was no evidence of anserine or an increase in 1-methylhistidine, which would have resulted from the hydrolysis of an anserine derivative or anserine. If a derivative of anserine is present in human muscles, it is not in a form readily hydrolyzed by acid.

\section{SUMMARY}

A method for the determination of anserine, carnosine, homocarnosine, histidine, 1-methylhistidine, and 3-methylhistidine with the Phoenix amino acid analyzer is described. A study of the separation of these compounds on the $60 \mathrm{~cm}$ column of the Beckman amino analyzer is also presented. The present method utilizing the Phoenix amino acid analyzer is particularly suitable for the analysis of muscle tissue extracts since in the range of elution volumes from 180 to $264 \mathrm{ml}$ there are no absorption peaks from muscle filtrates except those corresponding to the standard compounds listed above. It is of special importance that the elution of the $\mathrm{NH}_{4}{ }^{+}$, which may be present in the deproteinizing agents, occurs well beyond that of the histidine compounds.

\section{REFERENCES}

1. Kominz, D. R., Maruyama, K., Levenbook, L., and Lewis, M., Biochim. Biophys. Acta 63, 106 (1962).

2. Johnson, P., Harris, C. I.. Perry, S. V., Biochem. J. 105, 361 (1967).

3. Perry, T. L., Hansen, S., Tischler, B., Bunting, R., and Berry, K., New Engl. J. Med. 277, 1219 (1967).

4. Personal communication, Dr. Scriver.

5. Moore, S., Spackman, D. H., and Stein, W., Anal. Chem. 30, 1185 (1958).

6. Moore, S., Spackman, D. H., and Stein, W., Anal. Chem. 30, 1191 (1958).

7. Kuehl, W. M., and Adelstein, R. S., Biochem. Biophys. Res. Commun. 37, 59 (1969).

8. Long, C. L., And Geiger, J. W., Anal. Biochem. 29, 265 (1969).

9. Du Vigneatd, V., and Behrens, O., Ergeb. Physiol. 41, 917 (1939). 